\title{
Paste Dosage Form
}

National Cancer Institute

\section{Source}

National Cancer Institute. Paste Dosage Form. NCI Thesaurus. Code C42967.

A semi-solid composed of a large proportion of solids and finely dispersed active and/or inert ingredient(s) in a fat-based vehicle. 